\title{
Role of Next-Generation Sequencing as a Diagnostic Tool for the Evaluation of Bone and Soft-Tissue Tumors
}

\author{
Kinga Szurian Karl Kashofer Bernadette Liegl-Atzwanger
}

Klinisches Institut für Pathologie, Medizinische Universität Graz, Graz, Austria

\section{Keywords}

Next-generation sequencing · Molecular analysis .

Sarcomas $\cdot$ Bone tumors $\cdot$ Soft-tissue tumors

\begin{abstract}
Bone and soft-tissue tumors are in general rare. Diagnosing these tumors is challenging based on the significant number of different tumor entities, the rareness of these tumors, and the considerable morphological heterogeneity which can be found within a single tumor entity. Considering that more than half of the described soft-tissue tumors and approximately $25 \%$ of the bone tumors harbor recurrent genetic alterations, the use of auxiliary molecular examinations should be strongly considered. Molecular analyses are important to confirm the diagnosis, to guide treatment, to provide information about prognosis, and to allow patient recruitment for basket trials based on the molecular signature of a tumor. In addition, novel molecular alterations detected by nextgeneration sequencing (NGS) obtain further insights into the pathogenesis of these rare tumors and allow a more detailed genetic classification. Based on our single-center results of NGS using the Ion AmpliSeq Cancer Hotspot Panel v2 and the Ion AmpliSeq Comprehensive Cancer Panel (Thermo Fisher Scientific) for mutational analyses as well as
\end{abstract}

\section{KARGER}

(C) 2017 S. Karger AG, Basel

E-Mail karger@karger.com

www.karger.com/pat the Archer FusionPlex Sarcoma Kit (ArcherDX, Inc) to detect gene fusions in 26 genes since early 2016, we have experienced NGS as a very sensitive method to detect genetic alterations. In our experience, the use of the Archer FusionPlex Sarcoma Kit is superior to fluorescent in situ hybridization as an auxiliary tool in the routine workup of soft-tissue and bone tumors.

(c) 2017 S. Karger AG, Basel

\section{Introduction}

Bone and soft-tissue tumors are in general rare tumors. Malignant bone tumors account for only $0.2 \%$ of all malignancies, and soft-tissue sarcomas account for less than $1 \%$ of adult solid malignant tumors but add up to $20 \%$ of pediatric solid malignancies. Although patients with bone and soft-tissue sarcomas are commonly referred to academic centers where specialized physicians and supplementary molecular diagnostic methods are available, treatment of patients with these rare tumors is challenging. An interdisciplinary team of sarcoma specialists including orthopedic surgeons, radiologists, oncologists, pathologists, and radiation therapists are necessary to provide best care. A precise diagnosis has become

Kinga Szurian

Klinisches Institut für Pathologie, Medizinische Universität Graz Auenbruggerplatz 25

AT-8036 Graz (Austria)

E-Mail szuriankinga @ gmail.com or kinga.szurian@ medunigraz.at 
an integral part in more disease entities and guides personalized treatment of sarcoma patients. More than 117 different soft-tissue tumors and 58 bone tumors are defined in the recent WHO classification of bone and softtissue tumors [1]. The diagnosis of these tumors is challenging based on the significant number of different tumor entities, the rareness of these tumors, as well as the considerable morphological heterogeneity which can be found within a single tumor entity. In addition, limited biopsy material is complicating the precise pathological workup. Considering that more than half of the described soft-tissue tumors harbor recurrent genetic alterations, auxiliary molecular examinations should be strongly considered. Molecular analyses are important to confirm the given diagnosis based on morphology and immunohistochemistry (IHC) with an "independent" method, to guide treatment, to provide information about prognosis, as well as to allow patient recruitment for basket trials based on the molecular signature of a tumor. The number of new tumor entities described especially in soft-tissue tumors with defined molecular changes is still growing, and known tumor entities get better defined by the detection of recurrent molecular changes. Over the last years, evidence accumulated that the number of different fluorescent in situ hybridization (FISH) probes a laboratory needs to have for the adequate workup of soft-tissue tumors is rapidly increasing. However, based on the rareness of some tumor entities, commercially available FISH probes are not always available, which emphasizes the need for alternative molecular methods.

FISH is one of the most common auxiliary techniques used for the detection of chromosomal abnormalities. We routinely employ FISH analyses for soft-tissue tumors using commercially available dual-color fusion, break-apart, and amplification probes from ZytoVision $\mathrm{GmbH}$ to investigate chromosomal aberrations. Samples are evaluated according to the guidelines of Reference Laboratory at the Cleveland Clinic (for break-apart probes, optimal samples have a minimum of 40 tumor cells for analysis). In a positive test, $\geq 10 \%$ cells show a break-apart configuration of the 2 probes included in each of the individual assays, and in a negative test, $<10 \%$ break-apart signals are identified [2]. In case of MDM2 amplification, an MDM2/CEP12 ratio >2.0 is indicative of gene amplification $[3,4]$. However, defined cutoff levels for the evaluation of FISH for soft-tissue tumors and studies on interobserver variability for the interpretation of FISH examinations in soft-tissue tumors do not exist to the best of our knowledge. We especially experienced problems in examining FISH analyses of external speci- mens or limited material and when alternative fixatives were used. Using the EWSR1 break-apart probe, one of the most commonly used FISH probes, one should be aware that EWSR1 gene rearrangement can be seen in a large spectrum of benign and highly malignant tumors. Therefore, it is always necessary to corroborate FISH results with morphology and IHC. In addition, conflicting FISH results need to be confirmed by alternative techniques (real-time polymerase chain reaction [RT-PCR] or next-generation sequencing [NGS]). One should also keep in mind that in cases of SMARCB1-related deletions, unbalanced abnormalities in EWSR1 can be detected by FISH [5]. To determine not only the EWSR1 break-apart but also the EWSR1 fusion partner, at least 2 FISH examinations have to be performed. The necessity to have more than the commercially available spectrum of FISH probes as a referral center as well as the fact that is necessary to detect not only the break-apart but also the fusion partner increases the turn-around time and the cost factor. Therefore, we searched for alternatives and started to use NGS.

We are experienced in NGS using the Ion AmpliSeq Cancer Hotspot Panel v2 and the Ion AmpliSeq Comprehensive Cancer Panel (Thermo Fisher Scientific) for mutational analyses for several years as well as the Archer FusionPlex Sarcoma Kit (ArcherDX, Inc.) to detect gene fusions in 26 genes since early 2016. In our opinion, NGS is a very sensitive method to detect genetic alterations. Detection of fusion genes is a difficult task as break points are usually located in introns, which renders sequencing of the genomic DNA unfeasible. Instead, fusion analysis usually starts from the RNA where the exons of fusion products are in direct succession. The Archer FusionPlex Sarcoma Panel interrogates fusions involving 26 genes commonly altered in soft-tissue sarcomas from as little as 250 ng total RNA. In the Archer Fusion work flow, a single-sided PCR product is generated from cDNA starting in the exons of genes included in the assay (gene-specific primer). After initial elongation of the first strand, a linker sequence is ligated to the end of the PCR strand, which can then be used to amplify the PCR product. This reaction is highly multiplexed to allow the analysis of the 127 exons of the 26 genes. Sequencing of the PCR product can then be applied to reveal the fusion partner and thus allows to detect all gene fusions involving these exons, even novel fusions not yet known in the literature. The whole work flow is well automated and can be performed in 5 working days. The core biopsy bone specimens usually contain enough nucleic acids for molecular analysis. The regular decalcifying process with formic acid means a 
Table 1. Classification of bone and soft-tissue tumors according to molecular genetic categories

Tumors with a simple genome

Chimeric transcription factor or

transcriptional deregulation

Deregulated signaling

Epigenetic deregulation

Expression of oncometabolite via epigenetic deregulation

Tumors with a complex genome

Copy number alterations

Highly complex karyotype

ABC, aneurysmal bone cyst; BSNS, biphenotypic sinonasal sarcoma; DFSP, dermatofibrosarcoma protuberans; DSRCT, desmoplastic small round cell tumor; EH, epithelioid hemangioma; EHE, epithelioid hemangioendothelioma; ELS, Ewing-like sarcoma; EMC, extraskeletal myxoid chondrosarcoma; ES, Ewing sarcoma; GCTB, giant cell tumor of the bone; GIST, gastrointestinal stromal tumor; IMT, inflammatory myofibroblastic tumor; LGFMS, low-grade fibromyxoid sarcoma; LMS, leiomyosarcoma; LPF-NT, lipofibromatosis-like neural tumor; MCS, mesenchymal chondrosarcoma; OS, osteosarcoma ; PEComa, perivascular epithelioid cell neoplasm; PmHE, pseudomyogenic hemangioendothelioma; SEF, sclerosing epithelioid fibrosarcoma; SFT, solitary fibrous tumor; SS, synovial sarcoma; UPS, undifferentiated pleomorphic sarcoma; WD/DDLS, well-differentiated/dedifferentiated liposarcoma.
ABC, BSNS, DSRCT, EH, EHE, EMC, ES, ELS, LGFMS, LPF-NT, MCS, PEComa, PmHE, SEF, SFT, SS

DFSP, GIST, IMT

Chondroblastoma, GCTB, myoepithelial carcinoma, rhabdoid tumor, SS

Chondrosarcoma

LMS, low-grade OS, myxofibrosarcoma, postradiation angiosarcoma, UPS, WD/DDLS

Conventional osteosarcoma qualitative limitation for molecular examinations, but materials decalcified by EDTA are suitable for both FISH and NGS investigations. Using NGS, a highly sensitive method to detect genetic changes, a high number of novel genetic aberrations have been described in several bone and soft-tissue tumors. These findings can help to precisely diagnose these tumors and to obtain further insight into the pathogenesis of these rare tumors and will further allow a more detailed genetic classification of soft-tissue and bone tumors. In addition, comprehensive knowledge of underlying genetic changes will provide the basis for the development of targeted therapies, may define prognostic markers, and may help patients to participate in basket trials.

The following article is focusing on our single-center experience with NGS in the field of bone and soft-tissue tumors. We will summarize known molecular alterations in bone and soft-tissue tumors and will focus on the detection of recurrent molecular changes using NGS as a reliable method to detect fusions/mutations in the routine workup of these tumors.

Selected tumor entities where NGS analysis facilitates the diagnosis will be discussed.

NGS as a Diagnostic Tool for Bone and Soft-Tissue Tumors

\section{Overview}

In general, molecular classification divides soft-tissue sarcomas into two main categories: (i) sarcomas with specific genetic alterations (fusions, mutations, amplifications, and loss of a tumor suppressor gene) and (ii) sarcomas with complex karyotypic abnormalities (e.g. myxofibrosarcomas, leiomyosarcomas, and pleomorphic sarcomas) [6]. The molecular classification of herein-described bone and soft-tissue tumors is listed in Table 1 [7].

\section{Selected Bone Tumors with Recurrent Genetic Alterations That Can Facilitate a Precise Diagnosis}

\section{Chondroblastoma/Giant Cell Tumor of the Bone/ \\ Aneurysmal Bone Cyst}

Chondroblastoma is a primary, intermediate, rarely metastasizing bone tumor according to the recent WHO classification. It typically affects people in the second decade of life and is located at the epiphysis of long bones. Histologically, the tumor is composed of chondroblasts with abundant pink cytoplasm, chicken wire matrix with

Pathobiology 2017;84:323-338

DOI: $10.1159 / 000478662$ 
pink-bluish chondroid differentiation, and numerous osteoclast-type giant cells.

Giant cell tumor of the long bones (GCTB) is another primary, intermediate, rarely metastasizing bone tumor. This tumor occurs usually in individuals aged $20-40$ years and also has epiphyseal location sometimes spreading to the metaphysis. Microscopically, GCTB is composed of multinucleated osteoclast-like giant cells mixed with uniform mononuclear cells and foamy macrophages. Although its histological appearance can be worrisome with mononuclear, spindle cells, frequent mitoses, and intravascular spreading, these are not signs of malignancy.

These two lesions can be a diagnostic challenge on small biopsy specimens. IHC can be helpful but shows less specificity. Chondroblastomas can show positivity for $\mathrm{S} 100$ and SOX9, and specific, but weak and very limited, focal positivity for DOG1 [8-10]. In contrast, diffuse p63 positivity can support the diagnosis of giant cell tumor [11]. At least in our experience, IHC is of limited help in difficult cases. However, recent advances in molecular pathology using NGS demonstrated K36M mutations in the H3F3B gene in $95 \%$ of chondroblastomas and H3F3A mutations in $92 \%$ of giant cell tumors of the bones $[12,13]$. Both genes encode for histone H3.3 [14]. Also, in the rare variant of GCTB with symplastic/pseudoanaplastic changes which can mimic primary sarcoma or sarcomatous transformation, the same mutation as in conventional GCTB has been demonstrated [15]. Therefore, in our experience, mutational analysis using NGS is a very helpful technique to distinguish these tumor entities based on limited material.

Another differential diagnosis that could be considered in the context of giant cell-rich lesions is aneurysmal bone cyst $(\mathrm{ABC})$. This lesion occurs usually in individuals younger than 30 years in the metaphysis of the bone. It has also been described in the soft tissue. Histologically, the solid variant of $\mathrm{ABC}$ can closely mimic giant cell tumor of the bones. To be able to differentiate primary $A B C$ from giant cell tumor of the bones, mutational analysis demonstrating a H3F3A mutation or NGS demonstrating a USP6 fusion can facilitate the diagnosis [16]. Especially the use of a USP6 FISH probe can be very challenging as only a limited number of tumor cells demonstrate the USP6 translocation. Therefore, the interobserver variability is high, at least in our institution, and, in addition, diagnosis is complicated by a described range of USP6 rearrangement cells of 7-82\% [17]. Therefore, NGS using the Archer FusionPlex Sarcoma Kit is favorable to FISH analysis. In addition, in rare cases of telangiectatic osteosarcomas (OS) which can also mimic ABC, NGS might be of help in selected cases.

\section{Cartilaginous Tumors}

In general, cartilage-forming tumors are common. More than $60 \%$ of benign bone tumors are cartilageforming tumors. Amongst the malignant bone tumors, chondrosarcomas (CS) following OS are the second most common tumor entities and account for approximately $10-20 \%$ of all malignant primary bone tumors. Under the age of 30 years, the vast majority of cartilaginous tumors are benign, including enchondroma, chondroblastoma, osteochondroma, and chondromyxoid fibroma. In the age group between 30 and 40 years, beside enchondromas and osteochondromas, atypical cartilaginous tumor (ACT)/CS G1 and rarely central/peripheral CS are described. Over the age of 40 years, the most common cartilaginous tumor is ACT/CS G1, followed by high-grade CS and mesenchymal CS. Dedifferentiated CS can develop in a wide age range, but usually the patients are older than 50 years. Ollier disease and Maffucci syndrome are related to multiple enchondromas, and these patients show an increased risk to develop CS in younger age. Multiple osteochondroma is a genetic disease with autosomal dominant heritage. The lifetime risk of a malignant transformation in multiple osteochondroma is low $(<1 \%)$. Molecular changes in EXT1/EXT2 genes are known in osteochondromas as well as in secondary peripheral CS arising from osteochondromas. Multiple osteochondroma affects hedgehog signaling and upregulation of BCL2 [18].

Initially, IDH1 or IDH2 mutations were described in $81 \%$ of patients with Ollier disease and $77 \%$ of patients with Maffucci syndrome [19]. However, IDH1 or IDH2 mutations can also be detected in sporadic cartilaginous tumors in both central and periosteal enchondromas ( $21 \%$ of all cases) and in central CS (G1-2: 13\%, G3: 0\%) including dedifferentiated central CS (4\%). In contrast, no IDH mutations are observed in osteochondromas and peripheral CS [20]. Identification of IDH1/IDH2 mutations with NGS can be a useful tool in the diagnosis especially of dedifferentiated CS with limited G1 component and biopsy material exclusively obtained from the dedifferentiated component, a component with tremendous morphological heterogeneity [19-21]. In addition, IDH mutational analysis can also be very helpful to distinguish CS and chondroblastic OS since OS do not harbor somatic mutations in IDH1/IDH2 [22].

Moreover, detection of genetic changes in CS using NGS could also have clinical-translational relevance and improve diagnosis [23]. Speetnjens et al. [24] summarized the current clinical trials in CS patients. Several alterations in different pathways were recognized in CS, in- 
cluding alterations in IDH, hedgehog signaling, retinoblastoma protein, and $\mathrm{p} 53$. In part, these alterations might be the basis for selective targeted treatment modalities $[24,25]$.

\section{Low-Grade Central/Parosteal/Periosteal OS and} Fibrous Dysplasia

Low-grade OSs are rare tumors usually occurring in the third decade of life. They occur in different anatomic locations. Low-grade central OSs are usually located in the long bones, parosteal OS arises predominantly on the surface of the distal posterior femur, and periosteal OS arises typically in the diaphysis or dia-metaphysis as a sessile lesion. Fibrous dysplasia (FD), a benign medullary lesion in one or more bones (e.g., craniofacial bones and the femur) usually occurring in children and adults can histologically mimic low-grade OS [1]. Differential diagnosis between low-grade central OS and FD may be challenging based on pure morphology. Demonstration of MDM2 and CDK4 overexpression in low-grade OS using IHC/FISH is very helpful [26]. In contrast, FD, which is negative for MDM2 and CDK4, commonly demonstrates mutations in the GNAS gene, while all types of low-grade OS lack the GNAS mutation. To confirm the diagnosis of FD with GNAS mutation analysis may help to find a precise diagnosis [27].

\section{Soft-Tissue Tumors}

In this review, we are focusing only on subgroups of soft-tissue tumors to highlight the necessity of molecular investigation for a precise diagnosis and guidance of personalized therapy.

We will provide a summary about the diagnostic process of small round cell tumors (i), followed by perivascular epithelioid cell neoplasms (ii), subgroups of vascular tumors (iii), myxoid soft-tissue tumors (iv), and finally we summarize the diagnostic features of two recently described new entities (v).

\section{Small Round Cell Tumors}

Small round cell tumors represent a group of malignant neoplasms sharing histologically similar features. They are composed of small round cells with round nuclei containing fine chromatin and scanty clear or eosinophilic cytoplasm. Tumors within this category commonly occur in children and young adults. Tumors that should be considered in the differential diagnosis of small round cell tumors include: Ewing sarcoma (ES), Ewing-like sar-

NGS as a Diagnostic Tool for Bone and Soft-Tissue Tumors
Box 1. Specific translocations in small round cell tumors

$$
\begin{array}{cl}
\text { Ewing sarcoma-specific translocations: } \\
\begin{array}{cl}
\mathrm{t}(11 ; 22)(\mathrm{q} 24 ; \mathrm{q} 12) & \text { EWSR1-FLI1 } \\
\mathrm{t}(21 ; 22)(\mathrm{q} 22 ; \mathrm{q} 12) & \text { EWSR1-ERG } \\
\mathrm{t}(7 ; 22)(\mathrm{q} 22 ; \mathrm{q} 12) & \text { EWSR1-ETV1 } \\
\mathrm{t}(17 ; 22)(\mathrm{q} 12 ; \mathrm{q} 12) & \text { EWSR1-ETV4 } \\
\mathrm{t}(2 ; 22)(\mathrm{q} 33 ; \mathrm{q} 12) & \text { EWSR1-FEV } \\
\mathrm{t}(16 ; 21)(\mathrm{p} 11 ; \mathrm{q} 22) & \text { FUS-ERG } \\
\mathrm{t}(2 ; 16)(\mathrm{q} 35 ; \mathrm{p} 11) & \text { FUS/FEV }
\end{array}
\end{array}
$$

Ewing-like sarcoma-specific translocations:

$$
\begin{array}{ll}
\mathrm{t}(6 ; 22)(\mathrm{p} 21 ; \mathrm{q} 12) & \text { EWSR1-POU5F1 } \\
\operatorname{inv}(22)(\mathrm{q} 12) & \text { EWSR1-ZSG }(\mathrm{ZNF} 278) \\
\mathrm{t}(4 ; 22)(\mathrm{q} 31 ; \mathrm{q} 12) & \text { EWSR1-SMARCA } \\
\mathrm{t}(2 ; 22)(\mathrm{q} 31 ; \mathrm{q} 12) & \text { EWSR1-SP3 } \\
\mathrm{t}(1 ; 22)(\mathrm{p} 36.1 ; \mathrm{q} 12) & \text { EWS-ZNF278 } \\
\mathrm{t}(4 ; 19)(\mathrm{q} 35 ; \mathrm{q} 3) & \text { CIC-DUX4 } \\
\text { inv }(\mathrm{X})(\mathrm{p} 11.4 \mathrm{p} 11.22) & \text { BCOR/CCNB3 } \\
\text { Complex ring chromosome with amplification } \\
\text { of the translocated segments EWSR1-NFATc2 }
\end{array}
$$

comas (ELS), lymphomas, desmoplastic small round cell tumor, neuroblastoma, Wilms tumor, alveolar rhabdomyosarcoma, poorly differentiated monophasic synovial sarcoma, mesenchymal CS, melanoma, small-cell OS, and undifferentiated sarcoma with round cell morphology.

ES, ELS, and undifferentiated sarcoma with round cell morphology share the same histological features but harbor different specific translocations. Specific translocations in ES and ELS are listed in Box 1 [1,28-30].

For the diagnosis of ES, expanded IHC testing is necessary to exclude the mentioned differential diagnoses, and, in addition, molecular testing is mandatory. Tumors lacking the mentioned genetic changes should not be called ES. A group of tumors sharing morphological similarities to ES, however, that lack the typical genetic changes has been further subclassified in the last years. About two-thirds of EWSR1-negative small blue round cell tumors (SBRCT) are associated with CIC-DUX4-related fusions, whereas another small subset shows either BCOR-CCNB3 X-chromosomal paracentric inversion or a BCOR-MAML3 or the alternative ZC3H7B-BCOR fusion.

The CIC-DUX4 fusion-related tumors are morphologically characterized by tumor cells in large fragments or sheet-like growth. Tumor cells have ovoid-to-round hyperchromatic nuclei, occasionally prominent nucleoli, and moderate eosinophilic or clear cytoplasm, and are

Pathobiology 2017;84:323-338 DOI: $10.1159 / 000478662$ 
Table 2. Distinguishing features in small blue round cell tumors with clinical relevance

\begin{tabular}{|c|c|c|c|c|}
\hline Tumors & $\begin{array}{l}\mathrm{HE} \\
\text { staining }\end{array}$ & IHC & $\begin{array}{l}\text { Molecular } \\
\text { analysis }\end{array}$ & (Molecular) histology-based therapy ${ }^{1}$ \\
\hline Ewing sarcoma & & CD99+ & $\begin{array}{l}\text { Archer panel } \\
\text { NGS }\end{array}$ & $\begin{array}{l}\text { IGF } 1 \mathrm{R} \text { inhibitor with cixutumumab } \\
\text { and mTOR inhibitor, lurbinectedin } \\
\text { robatumumab, dalotuzumab }+/- \\
\text { ridaforolimus } \\
\text { Mutations in PTPRD, GRB10, KRAS }\end{array}$ \\
\hline Ewing-like sarcoma & & $\begin{array}{l}\text { CD99+WT1+/- } \\
\mathrm{CCNB}+/-\mathrm{BCOR}+/-\end{array}$ & $\begin{array}{l}\text { Archer panel } \\
\text { NGS }\end{array}$ & $\begin{array}{l}\text { IGF 1R inhibitor with cixutumumab } \\
\text { and mTOR inhibitor }\end{array}$ \\
\hline Neuroblastoma & & CD99+CD56+ & $\begin{array}{l}\text { FISH N-MYC } \\
\text { amplification }\end{array}$ & \\
\hline Rhabdomyosarcoma & & $\begin{array}{l}\text { Desmin+MYF4+ } \\
\text { Myogenin+PAX5+/- }\end{array}$ & $\begin{array}{l}\text { Archer panel } \\
\text { NGS }\end{array}$ & \\
\hline $\begin{array}{l}\text { Undifferentiated small cell } \\
\text { sarcoma }\end{array}$ & & CD99+/- & $\begin{array}{l}\text { Archer panel } \\
\text { NGS }\end{array}$ & \\
\hline Synovial sarcoma & & $\begin{array}{l}\text { TLE1+CK+(focal) } \\
\text { EMA+(focal) }\end{array}$ & $\begin{array}{l}\text { Archer panel } \\
\text { NGS }\end{array}$ & \\
\hline Lymphoma/leukemia & & $\begin{array}{l}\text { CD } 45+(-) \text { CD79a+ } \\
\text { Other markers: } \\
\text { depending on subtype }\end{array}$ & $\begin{array}{l}\text { Depending on } \\
\text { subtype }\end{array}$ & \\
\hline Small cell osteosarcoma & Osteoid & & & \\
\hline $\begin{array}{l}\text { Mesenchymal } \\
\text { chondrosarcoma }\end{array}$ & Cartilage & CD99+/- & $\begin{array}{l}\text { Archer panel } \\
\text { NGS }\end{array}$ & \\
\hline $\begin{array}{l}\text { Desmoplastic small } \\
\text { round cell tumor }\end{array}$ & Desmoplasia & $\begin{array}{l}\text { CD99+(-) FLI1+ } \\
\text { Desmin+/- CK+/- } \\
\text { NSE+/- }\end{array}$ & $\begin{array}{l}\text { Archer panel } \\
\text { NGS }\end{array}$ & $\begin{array}{l}\text { Pazopanib, sunitinib, IGF-1R } \\
\text { inhibitor with cixutumumab and } \\
\text { mTOR inhibitor } \\
\text { Mutations in PTPRD, GRB10, KRAS }\end{array}$ \\
\hline
\end{tabular}

${ }^{1}$ Potential therapy targets are shown in italics.

embedded in a fibrous stroma. In some cases, myxoid stroma was also observed. Geographic tumor necrosis is also frequently found. In comparison with ES, round cell sarcoma with CIC-DUX4 fusion demonstrates more cytological atypia [31]. The BCOR-CCNB3-positive tumors preferentially occur in children and in the bone in contrast to alternative BCOR-rearranged SBRCT, which develop later, in young adults, with a variable anatomic distribution. Histologically, BCOR-rearranged tumors often contain spindle cell areas and show a histological overlap with poorly differentiated synovial sarcoma [32]. In contrast, areas of spindle cells arranged in fascicles are usually not present in CIC-DUX4-related SBRCT. These tumors also contain tumor cells with vesicular nuclei, with distinct, often enlarged nucleoli, but lacking a higher degree of heterogeneity, which is typical for other tumors in the ES family [33]. IHC may facilitate the diagnosis of ELS, e.g., WT1 positivity in CIC-DUX4-associated sarcomas [33-35] or CCNB3 or BCOR staining to distinguish BCOR-CCNB3-associated sarcomas from other ELS [36,
37]. Further specific immunostaining to differentiate SBRCT is listed in Table 2.

The differential diagnosis in the ES and ELS group is challenging based on the morphological variability and limited specific IHC markers. NGS is, therefore, a powerful tool to classify the group of ES and ELS based on their underlying molecular changes [33].

Desmoplastic small round cell tumor is a highly malignant mesenchymal tumor. Its peak incidence is in the third decade of life, but with a wide age range from the first to the fifth decade. A striking male predominance is observed. The majority develops in the abdominal cavity. Beside containing small round cells, these tumors usually demonstrate prominent stromal desmoplasia. Multiphenotypic differentiation with expression of epithelial, muscular and neural markers is well known. Staining with antibodies against CK, EMA, desmin (dot-like), and NSE may vary in extent. The demonstration of a recurrent translocation $\mathrm{t}(11 ; 22)(\mathrm{p} 13 ; \mathrm{q} 12)$ resulting in EWSR1WT1 fusion is typical for this tumor entity. 

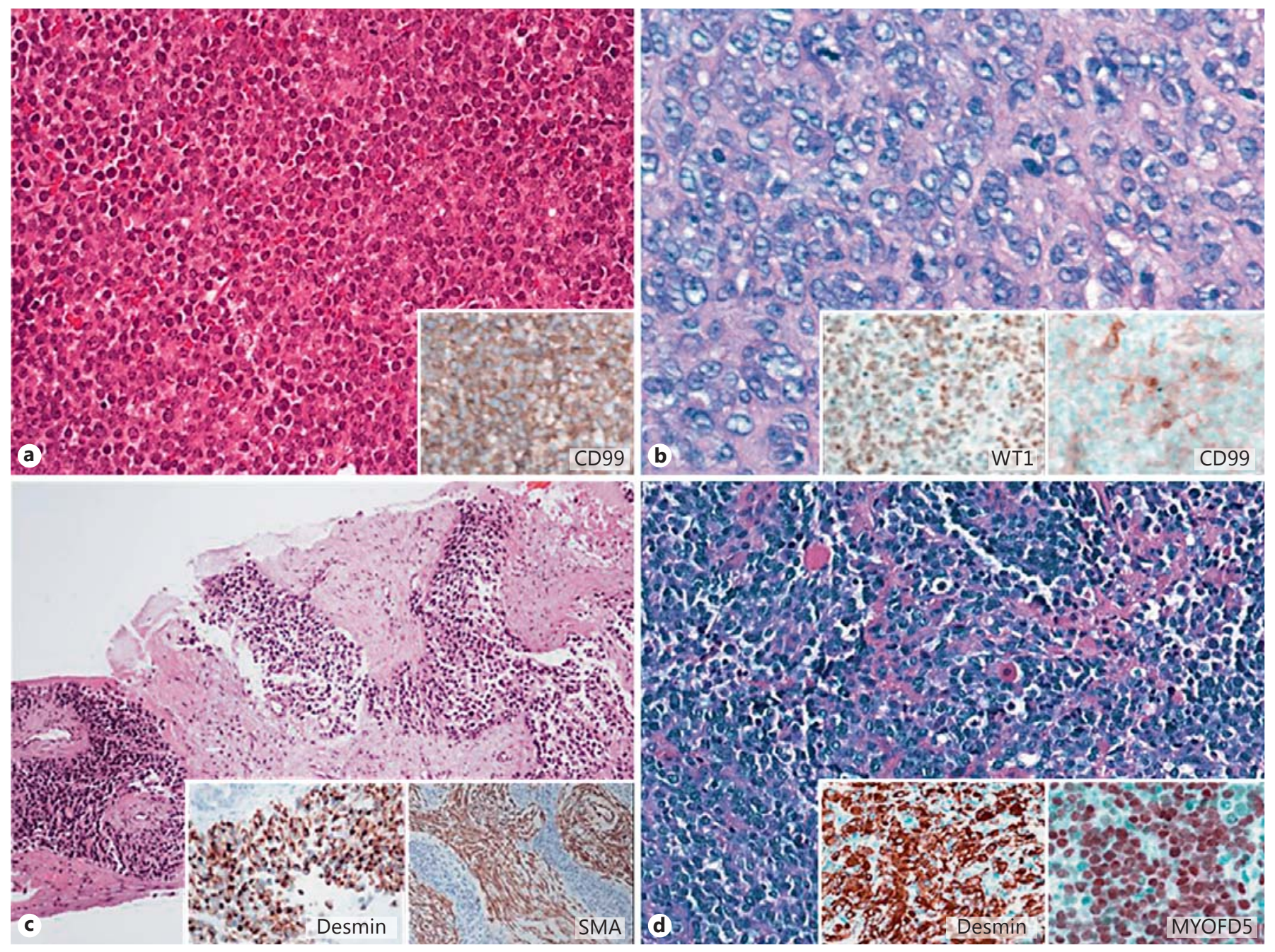

Fig. 1. Histological and immunohistochemical features of small round cell tumors. a Ewing sarcoma. b. CICDUX4 translocation-associated Ewing-like sarcoma. c Desmoplastic small round cell tumor. d Solid alveolar rhabdomyosarcoma.

Mesenchymal CS is a malignant tumor with biphasic pattern, containing undifferentiated round cells and well-differentiated hyaline cartilage. It can occur at any age but preferentially occurs in the second and the third decade. Besides widespread skeletal distribution, extraskeletal involvement with meningeal origin is well known. Recently, two fusion genes were described in mesenchymal CS: the HEY1-NCOA2 fusion and the IRF2BP2-CDX1 fusion [38, 39]. Because of the overlapping morphological features in meningeal hemangiopericytoma and mesenchymal CS, identification of the HEY1-NCOA2 fusion, which is not present in meningeal hemangiopericytoma, is inevitable for the diagnosis of mesenchymal CS [40].

NGS as a Diagnostic Tool for Bone and Soft-Tissue Tumors
In addition to its diagnostic role, NGS may confirm the presence of mutations and translocations, which are potential targets of molecular-based personalized treatment options in ES or desmoplastic small round cell tumor (Table 2) [41-50]. Histological and IHC features of SBRCT are shown in Figure 1. Other SBRCT subsets mentioned above are not described in more detail in this issue.

\section{Perivascular Epithelioid Cell Neoplasms}

Perivascular epithelioid cell neoplasms (PEComa) are a family of rare mesenchymal tumors with perivascular epithelioid cell differentiation expressing myo-melanocytic markers. The PEComa family includes angiomyolipoma, clear-cell "sugar" tumor of the lung, and lymphan-

Pathobiology 2017;84:323-338

DOI: $10.1159 / 000478662$ 
gioleiomyomatosis. A subset of tumors with identical histological features occurs in the soft tissue or visceral sites. Most commonly, they arise in the retroperitoneal or pelvic region as well as in the uterus or in the gastrointestinal tract. These tumors occur in all age groups, but they are most common in young to middle-aged adults. Microscopically, PEComas are composed of epithelioid cells with abundant eosinophilic or clear cytoplasm arranged in small nests surrounded by capillary vessels. They typically express HMB45, Melan-A, MITF, SMA, and desmin. The distinction between "benign" and "malignant" tumors is based on mitotic activity, necrosis, marked nuclear atypia, and pleomorphism. Although most PEComa harbor loss-of-function mutations in TSC1/TSC2, a small subset carries TFE3 gene rearrangement [1]. SFPQ/PSFTFE3 gene fusions were previously reported by Tanaka et al. [51]. In addition, a novel DVL2-TFE3 gene fusion was also described. Based on a recent publication, PEComa with a TFE3 gene abnormality shows strong TFE3 and cathepsin $\mathrm{K}$ immunoreactivity and weak-to-strong reactivity for HMB45 [52-54]. The diagnosis of PEComa is usually based on HE-stained slides combined with IHC. However, identification of the underlying genetic alterations could be necessary to assess the prognosis and to determine the best treatment option. In a clinical followup study, Agaram et al. [55] demonstrated that PEComa patients with TFE3 rearrangement may have a better prognosis. In patients with TSC $1 / 2$ mutation, mTOR inhibitors have proven to be effective $[56,57]$. Especially in patients suffering from malignant/metastatic PEComa, NGS may provide further insight regarding potential treatment strategies.

\section{Vascular Tumors}

In the last years, tremendous efforts in the classification of vascular tumors have been achieved by detecting recurrent genetic changes. The group of vascular tumors contains several entities showing endothelial differentiation with diverse patterns in bone and soft tissue. This article is restricted to vascular lesions where molecular analysis is of diagnostic and/or prognostic relevance.

Epithelioid Hemangioma. In contrast to epithelioid hemangioma (EH) of the soft tissue, $\mathrm{EH}$ of the bone is a locally aggressive tumor occurring in patients with a wide age range. The tumors are usually located in long tubular bones or affect flat bones, vertebrae, or small bones of the hands. Regional multifocal forms can occur. Histologically, these tumors show a lobular architecture with typically small vessels at the periphery. Besides solid sheets of epithelioid tumor cells, vascular structures lined with ep- ithelioid cells are observed. Small foci of necrosis and fascicles of proliferating spindle cells may be seen, and nuclear atypia can be present [1]. In biopsy material, where the architecture is sometimes hard to evaluate, the distinction between $\mathrm{EH}$ and malignant vascular tumors may be challenging. Recently, FOS rearrangement has been described in an EH subset, presumably in correlation with morphological appearance and the involved site. Huang et al. [58] have demonstrated FOS rearrangement in a third of $\mathrm{EH}$, with increased prevalence in intraosseous ( $59 \%$ of intraosseous EH) and cellular EH (70\% of all FOS-rearranged EH). In a study by Antonescu et al. [59], FOSB rearrangement was observed in $20 \%$ of EH. Morphologically, tumors with FOSB rearrangement contained solid areas, increased cellularity, and nuclear pleomorphism. Fusion-negative EH were less cellular, had less solid components, and lacked cytological atypia helping to distinguish $\mathrm{EH}$ with atypia from angiosarcoma (AS) by detecting FOSB rearrangement. Molecular investigation of FOS gene rearrangement, if present, can significantly facilitate the diagnosis of $\mathrm{EH}$, especially in cases with nuclear atypia. However, the absence of a FOS gene rearrangement, on the other hand, does not exclude $\mathrm{EH}$, because this genetic change is only seen in up to one third of cases. Therefore, in the absence of FOS rearrangement, the distinction between $\mathrm{EH}$ with cytological atypia and other malignant vascular tumors remains still challenging.

Pseudomyogenic Hemangioendothelioma. Pseudomyogenic hemangioendothelioma is a rarely metastasizing vascular tumor occurring most commonly in young male adults. This tumor occurs usually in the extremities; in approximately $50 \%$ of cases, it can be located multicentric in different tissue planes. The tumor is histologically composed of plump spindle cells with abundant eosinophilic cytoplasm mimicking myoid or epithelioid differentiation, which is arranged in sheets and fascicles. The tumor cells express keratin AE1/AE3, FLI1, and ERG, and $30 \%$ of the tumors show focal positivity for SMA. Staining for CK-MNF116, EMA, S100, CD34, and desmin is negative in the tumor cells. FOSB rearrangement is also described in subsets of pseudomyogenic hemangioendotheliomas [60-62].

Epithelioid Hemangioendothelioma. Epithelioid hemangioendothelioma (EHE) is a malignant vascular neoplasm that develops mostly after the second decade of life. It arises usually in the soft part of the extremities in angiocentric location. Intraosseous EHE occurs mostly in the long tubular bones. The tumor is composed of epithelioid endothelial cells embedded in myxohyaline stroma 
growing in an angiocentric distribution. Besides WWTR1CAMTA1 rearrangement in EHE subsets, YAP1-TFE3 rearrangement is noted $[1,63,64]$. IHC identification of CAMTA expression [65] as well as IHC demonstration of TFE3 can be also helpful to differentiate EHE from AS.

Postradiation AS. AS is a malignant vascular tumor of the elderly. Most often, AS arises from the deep soft tissue of the extremities, but intraosseous tumors with wide skeletal distribution are also described. AS subsets are associated with previous irradiation [1]. Radiotherapy-associated vascular proliferation covers a range of benign and malignant tumors. Atypical vascular lesions (AVL) are macroscopically composed of small papules with discoloration. Usually, they develop short after radiation therapy (median 3 years). AVL are located in the superficial or mid-dermis, and, in a few cases, AVL extend to the deep dermis, without subcutaneous infiltration. It is a well-circumscribed, but unencapsulated lesion composed of anastomosing vascular channels. The endothelial cell nuclei are hyperchromatic with prominent hobnailing. Cytological atypia, mitosis, necrosis, or multilayering of endothelial cells are not present. Vascular channels are often more compressed in the deeper counterpart. AVL show morphological overlap with well-differentiated AS, but so far their clinical behavior was reported to be benign. AS shows microscopically evident signs of malignancy, atypical cells with prominent nucleoli, mitoses, papillary endothelial hyperplasia, and "blood lakes." Infiltration into the subcutis and dissection of dermal collagen are also present. Well-differentiated AS can also contain AVL-resembling areas with anastomosing vascular channels and focal endothelial hobnailing without cytological atypia or multilayering. It is challenging to differentiate these two lesions in HE-stained slides of a small biopsy [66]. Mentzel et al. [67] have found MYC amplification in postradiation cutaneous AS, whereas control cases and cases of atypical vascular proliferation after radiotherapy were negative for MYC. Using IHC, strong positive nuclear staining for MYC was seen in cases of postradiation cutaneous AS, in contrast to atypical vascular proliferations. Cornejo et al. [68] confirmed that detection of MYC protein expression by IHC and MYC gene amplification by FISH are valuable to distinguish AVL from postradiation AS. Moreover, MYC immunostaining is helpful to control resection margins [67].

\section{Myxoid Soft-Tissue Tumors}

Myxoid soft-tissue tumors represent a wide group of tumors with benign to malignant behavior. In the following paragraph, we will focus on tumors where molecular

NGS as a Diagnostic Tool for Bone and Soft-Tissue Tumors
Box 2. Summary of myxoid soft-tissue neoplasms with molecular diagnostic relevance
Benign tumors
Nodular fasciitis
Intermediate tumors
Myxoinflammatory fibroblastic sarcoma/tumor
Dermatofibrosarcoma protuberans
Solitary fibrous tumor
Malignant tumors
Myxofibrosarcoma
Low-grade fibromyxoid sarcoma
Myxoid liposarcoma
Extraskeletal myxoid chondrosarcoma
Myoepithelial carcinoma
Myxoid synovial sarcoma

examination is a useful diagnostic tool. A summary of these lesions is given in Box 2 .

Myxoinflammatory Fibroblastic Sarcomas/Tumors. They are locally aggressive tumors usual occurring at acral sites most commonly in the distal extremities and typically occur in middle-aged people [1]. Myxoinflammatory fibroblastic sarcoma/tumor is composed of moderately cellular nodules with basophilic myxoid matrix alternating with fibrohyaline matrix. They are composed of 3 distinct types of tumor cells: large Reed-Sternberg or virocyte-like cells, spindle-to-epithelioid mononuclear tumor cells, and so-called "pseudolipoblasts" with abundant vacuolated myxoid basophilic cytoplasm. Hallmark of the lesion is the prominent mixed acute and chronic inflammatory cell infiltrate rich in eosinophils, neutrophils, lymphocytes, and plasma cells. Diagnosis is based on HE morphology while IHC is of limited use. To exclude inflammatory conditions or other myxoid soft-tissue tumors, NGS can be performed to demonstrate a MGEA5-TGFBR3 fusion [69].

Myxofibrosarcoma. Myxofibrosarcoma is one of the most common sarcomas in elderly patients, usually arising in the limbs. Histologically, the hallmarks of this tumor are curvilinear blood vessels with accentuated atypical spindle cells in a myxoid background. Hypercellular solid sheets and fascicles of spindle as well as pleomorphic tumor cells may be present in variable ratio in correlation with histological grade. Because of the lack of specific immunostaining and specific genetic alterations, the diagnosis is mainly based on HE morphology and differential diagnoses need to be excluded. Especially in low-grade tumors, a myxoid variant of dermatofibrosarcoma

Pathobiology 2017;84:323-338

DOI: $10.1159 / 000478662$
331 


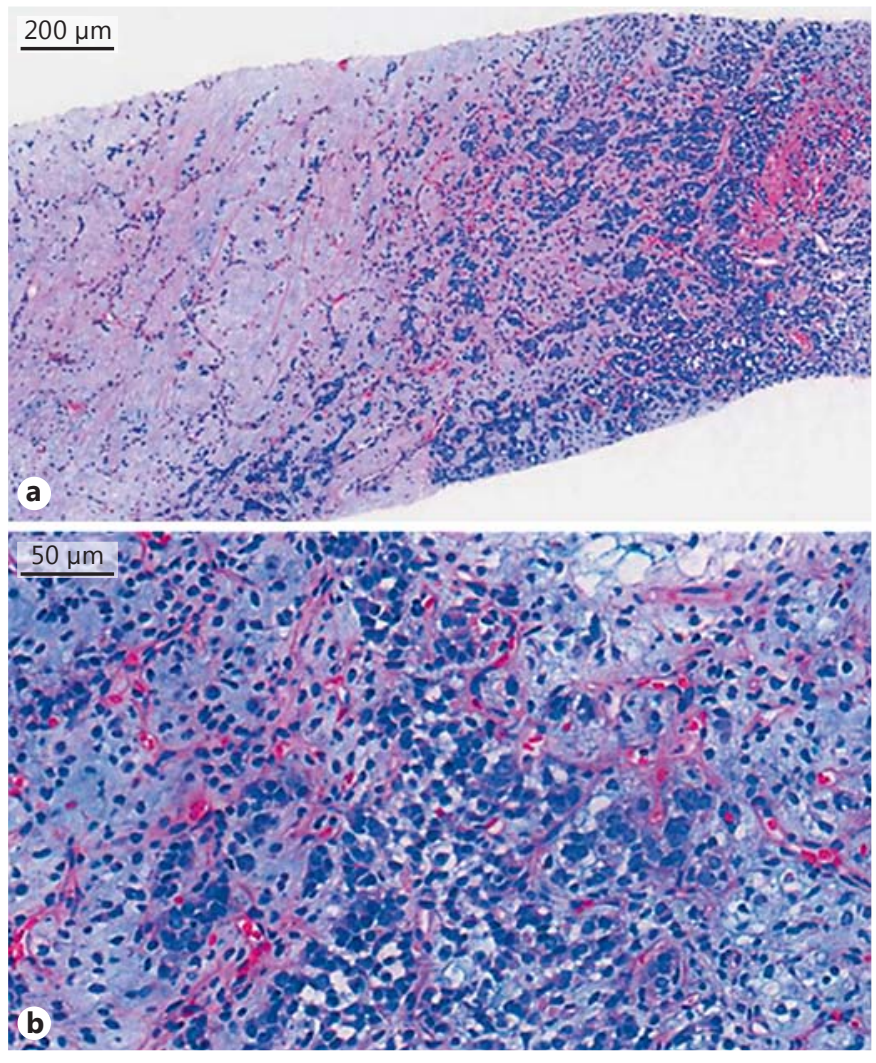

Fig. 2. Myxoid liposarcoma, nested variant. HE. $\mathbf{a} \times 10$. $\mathbf{b} \times 40$.

protuberans (DFSP), low-grade fibromyxoid sarcoma (LGFMS), or a cellular myxoma are included in the differential diagnosis. The demonstration of a PDGFRBCOL1A1, FUS-CREB3L1, and FUS-CREB3L2 fusion, or a mutation in the GNAS gene can facilitate the diagnosis of the mentioned differential diagnoses.

Low-Grade Fibromyxoid Sarcoma. LGFMS is a lowgrade malignant sarcoma with morphological overlap especially with benign mesenchymal lesions. Most of the reported cases affect young adults, and it is typically located in the proximal extremities or trunk. Although this is a low-malignant sarcoma, a long-term follow-up is required due to the occurrence of late metastases. LGFMS and a subset of sclerosing epithelioid fibrosarcomas harbor the same chromosomal translocation with FUSCREB3L2 or FUS-CREB3L1 rearrangement. There are several other tumors with recurrent translocations, involving the FUS gene, e.g., myxoid liposarcoma or angiomatoid fibrous histiocytoma [70, 71]. Detection of MUC4 expression by IHC is a very powerful tool to confirm the diagnosis of LGFMS. The presence of MUC4 expression is also observed in sclerosing epithelioid fibrosarcoma,

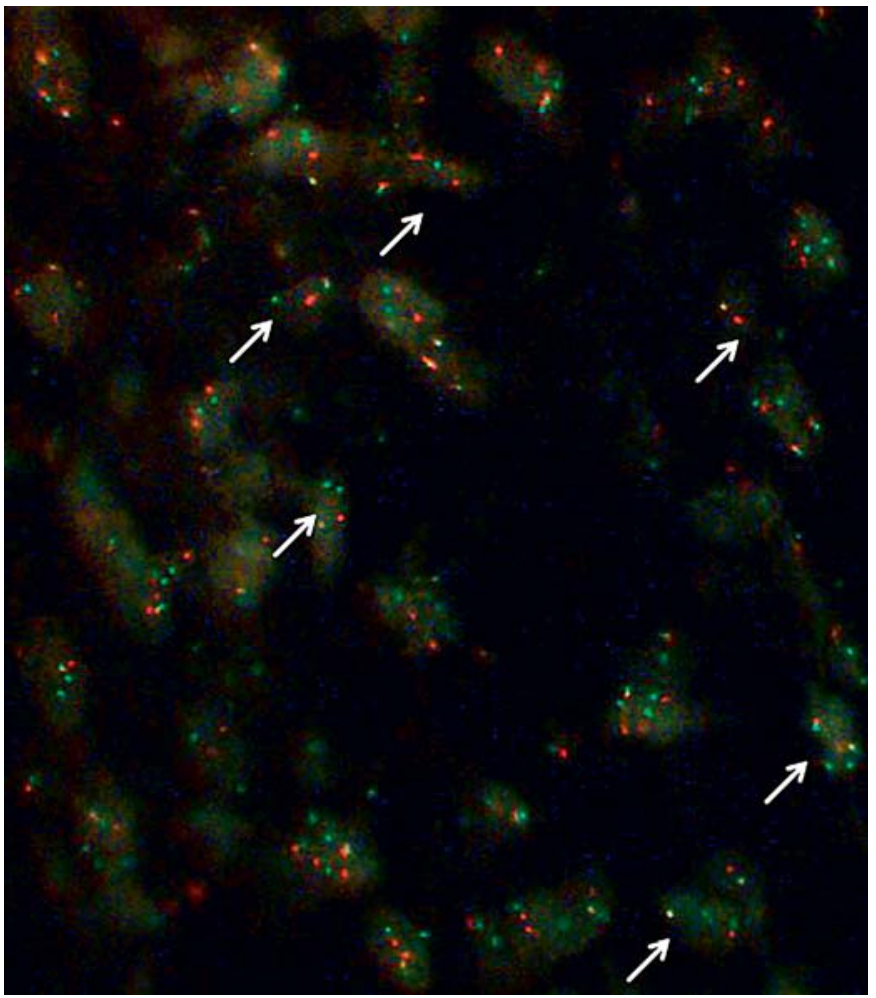

Fig. 3. Myxoid liposarcoma. FISH showing a CHOP break-apart signal (arrows).

but MUC4 staining does not predict the presence of FUS rearrangement, as only $40 \%$ of MUC4-positive sclerosing epithelioid fibrosarcomas show FUS rearrangement [72, 73].

Myxoid Liposarcoma. It accounts for $20 \%$ of liposarcomas and typically arises in the deep soft tissue of the extremities of children and adolescents. Microscopically, low-grade myxoid liposarcoma is composed of monomorph round-to-ovoid cells in a myxoid background with arborizing "chicken wire" capillaries. Various morphological patterns, e.g., traditional myxoid, traditional round cell, pulmonary edema-like, lipoblast-rich, island, lipomatous, stromal hyalinization, cord-like, nested (Fig. 2), chondroid metaplasia, and hemangiopericytoma-like patterns, have been described [74]. The lack of specific IHC markers as well as the morphological heterogeneity underlines the use of FISH (Fig. 3) or NGS to demonstrate FUS-DDIT3 or EWSR1-DDIT3 fusions in this tumor entity.

Dermatofibrosarcoma Protuberans. DFSP is a lowgrade, locally aggressive fibrohistiocytic tumor with recurrent COL1A1-PDGF fusion. It develops in young to 
middle-aged adults typically superficial in the trunk or proximal extremities. Usually, DFSP shows a typical morphological pattern of a hypercellular tumor composed of uniform spindle cells arranged in a storiform pattern and infiltrates the subcutaneous adipose tissue in a so-called "honeycomb pattern." The diffuse CD34 positivity is very helpful in diagnosing DFSP [1]. The diagnosis of the myxoid variant of DFSP, however, may be challenging. As neoadjuvant imatinib mesylate may be of benefit in unresectable tumors or in reducing tumor size, molecular testing for a COL1A1-PDGF fusion to confirm the diagnosis as well as to predict therapy response should be performed [71].

Extraskeletal Myxoid CS/Myoepithelial Carcinoma. Extraskeletal myxoid CS (EMC) is a malignant tumor of unknown origin occurring in adults, usually in the deep soft tissue of the proximal extremities or limb girdles. Morphologically EMC is a multinodular tumor displaying cords of uniform tumor cells in an abundant myxoid matrix. Myoepithelial tumors of the soft tissue are rare. Histologically, these tumors show a wide morphological spectrum and are similar to their salivary gland counterparts. EMC and myoepithelial carcinoma demonstrate morphological similarities and an overlap in the IHC profile. Therefore, demonstrating specific reciprocal translocations, involving the NR4A3 gene with the fusion partners EWSR1, TAF15, TCF12, and TGF, can support the diagnosis of EMC. In contrast, loss of SMARCB1/INI1 is a typical alteration in the majority of myoepithelial carcinomas [75-78]. Taking into account that SMARCB1/ INI1 and EWSR1 genes are located close to each other on chromosome 22, larger SMARCB1 deletions may encompass the EWSR1 locus, which can lead to misinterpretation by FISH analysis. This reveals the necessity of NGS in significant subgroups of tumors with EWSR rearrangement [5]. Especially in myxoid soft-tissue tumors, NGS can facilitate a precise diagnosis especially on biopsy material by demonstrating recurrent gene fusions or mutations [79].

\section{Recently Described New Entities of the Soft Tissue}

Lipofibromatosis-Like Neural Tumor. The group of pediatric fibroblastic and myofibroblastic tumors contains a wide spectrum of entities; histologically, features can overlap with sarcomas, such as infantile fibrosarcoma or spindle-cell rhabdomyosarcoma. Among the superficial lesions, lipofibromatosis (LPF), composed of adipose tissue and fibroblastic elements, has so far been diagnosed as infantile fibromatosis or fibrous hamartoma of infancy. LPF-like neural tumor (NT) affects young children and develops usually in the soft tissue of the trunk or distal extremities. Local recurrence is often due to the highly infiltrative growth pattern with subsequent incomplete resection. Immunohistochemically, these tumors are CD34 and SMA positive and stain negative for other markers. Recently, a tumor with similarities on morphological examination located in a wide anatomic distribution has been described with variable cytological atypia and at least focal-positive staining for S100. This tumor is composed of plump spindle cells arranged in fascicles infiltrating the subcutaneous adipose tissue. The tumor cells show eosinophilic cytoplasm and fusiform nuclei with mild hyperchromasia. Mitotic activity is low $(<2 / 10 \mathrm{HPF})$, and necrosis has not been reported. Beside S100 expression, CD34 and variable SMA expression has been reported. No staining with antibodies against desmin, GFAP, STAT6, HMB45, Melan-A, and SOX10 was reported. Agaram et al. [80] reported a TPR-NTRK1 or TPM3-NTRK1 gene fusion in $71 \%$ of cases. Furthermore, the performed NTRK1 immunostaining was positive only in NTRK1-rearranged S100-positive LPF-NT but negative in classic LPF. These results suggest that NTRK1 oncogenic activation through gene fusion defines a novel and distinct entity, provisionally named LPF-NT; expanded IHC analysis including NTRK1, S100, CD34, CK, and myogenic markers is helpful to diagnose this tumor in addition with molecular diagnostics.

PAX3 Fusion-Positive Biphenotypic Sinonasal Sarcoma. PAX3 fusion positive biphenotypic sinonasal sarco$\mathrm{ma}$ (BSNS) is a recently described, low-grade sarcoma developing in the sinonasal region, mostly in the nasal cav-

\section{(Footnote to Table 3.)}

$\mathrm{ABC}$, aneurysmal bone cyst; $\mathrm{AFH}$, angiomatoid fibrous histiocytoma; AS, angiosarcoma; ASPS, alveolar soft part sarcoma; BSNS, biphenotypic sinonasal sarcoma; cc., carcinoma; CCS, clear-cell sarcoma; DF, deep-type fibromatosis; DFSP, dermatofibrosarcoma protuberans; EH, epithelioid hemangioma; EHE, epithelioid hemangioendothelioma; EMC, extraskeletal myxoid chondrosarcoma; ES, epithelioid sarcoma; f, focal; GCTB, giant cell tumor of the bone; GIST, gastrointestinal stromal tumor; IMT, inflammatory myofibroblastic tumor; LGFMS, low-grade fibromyxoid sarcoma; LMS, leiomyosarcoma; LPF-NT, lipofibromatosis-like neuronal tumor; MFS, myxofibrosarcoma; MIFS, myxoinflammatory fibroblastic sarcoma; MLS, myxoid liposarcoma; MPNST, malignant peripheral nerve sheath tumor; OS, osteosarcoma; PEComa, perivascular epithelioid-cell tumor; PmHE, pseudomyogenic hemangioendothelioma; RMS, rhabdomyosarcoma; SEF, sclerosing epithelioid fibrosarcoma; SFT, solitary fibrous tumor; SMA, smooth muscle actin; SS, synovial sarcoma; TSGCT, tenosynovial giant cell tumor.

${ }^{1}$ Fusions are in normal font; mutations, amplifications, overexpression, and loss of functions are in italics. ${ }^{2}$ Potential therapy targets are in italics.

Pathobiology 2017;84:323-338

DOI: $10.1159 / 000478662$ 
Table 3. Differential diagnostic guidelines of bone and soft-tissue neoplasms according to genetic alterations and therapeutic relevance

\begin{tabular}{|c|c|c|c|}
\hline & Genetic alterations $^{1}$ & Immunohistochemistry & (Molecular) histology-based therapy ${ }^{2}$ \\
\hline \multicolumn{4}{|l|}{ Bone tumors } \\
\hline $\mathrm{ABC}$ & USP6-CDH11 & & \\
\hline GCTB & $H 3 F 3 A$ & p63+ & \\
\hline Chondroblastoma & $H 3 F 3 B$ & S100+/-SOX9+ DOG1 f+/- H3F3 K36m+ & \\
\hline Chondrosarcoma & IDH1/IDH2 mutation & IDH1/IDH2 m (R132/172) f+ & $S H H, B C L 2, I D H, R b$ \\
\hline Low-grade OS & MDM2/CDK4 amplification & $\mathrm{MDM} 2+\mathrm{CDK} 4+$ & \\
\hline Fibrous dysplasia & GNAS mutation & & \\
\hline OS & EZH2 overexpression in advanced cases & $\mathrm{SATB} 2+\mathrm{EZH} 2+/-$ & \\
\hline \multicolumn{4}{|l|}{ Soft-tissue tumors } \\
\hline \multirow[t]{2}{*}{ PEComa } & SFPQ/PSF-TFE3 DVL2-TFE3 & HMB45+ Melan-A+ SMA+ TFE3+/- & mTOR inhibitors \\
\hline & TSC1/TSC2 mutation & Cathepsin K+ PAX8- & \\
\hline \multicolumn{4}{|l|}{ Vascular neoplasms } \\
\hline $\mathrm{EH}$ & ZFP36-FOSB & & \\
\hline PmHE & SERPINE1-FOSB & & \\
\hline EHE & WWTR1-CAMTA1 YAP1-TFE3 & CAMTA1+/- TFE3+/- & \\
\hline Postradiation AS & MYC amplification & $\mathrm{MYC}+$ & Sorafenib, taxanes, gemcitabine \\
\hline \multicolumn{4}{|l|}{ Myxoid neoplasms } \\
\hline MIFS & & Excluding & \\
\hline MFS & & Excluding & \\
\hline LGFMS & FUS-CREB3L2 or FUS-CREB3L1 & MUC4+ & \\
\hline MLS & FUS-DDIT3/EWSR1-DDIT3 & & Trabectidin \\
\hline DFSP & COL1A1-PDGF & CD34+ & Imatinib \\
\hline EMC & NR4A3-EWSR1/TAF15/TCF12/TGF & & \\
\hline Myoepithelial cc. & Loss of SMARCB1/INI1 & INI1- & \\
\hline Nodular fasciitis & USP6-MYH9 & & \\
\hline SFT & NAB2-STAT6 & STAT6+ & Sunitinib \\
\hline \multicolumn{4}{|c|}{ Non-myxoid neoplasms } \\
\hline SEF & FUS-CREB3L2 & MUC4+ & \\
\hline IMT & EML4-ALK, TFG-ROS1, RET rearr. & $\mathrm{ALK}+/-$ & Crizotinib, kinase fusions \\
\hline DF & CTNNB1 mutation & $\beta$-Catenin + & \\
\hline MPNST & $\begin{array}{l}\text { SUZ12, EED, EGFR, IGF1R, SOX9, } \\
\text { EYA4, TOP2A, ETV4, BIRC5 }\end{array}$ & S100f+ Leu7f+ MyoD1/MYF4f+/- & $\begin{array}{l}\text { EGFR, IGF1R, SOX9, EYA4, TOP2A, } \\
\text { ETV4, BIRC5 }\end{array}$ \\
\hline \multicolumn{4}{|l|}{ New entities } \\
\hline LPF-NT & NTRK1-TPR/TPM3 & S100+ & \\
\hline BSNS & PAX3-AML3/NCOA1/FOXO1 & S100+ $\beta$-catenin + SOX10+ & \\
\hline & MAML3-non-PAX3 & & \\
\hline \multicolumn{4}{|l|}{ Others } \\
\hline $\mathrm{AFH}$ & EWSR1-CREB1/FUS-ATF1/EWSR1-ATF1 & & \\
\hline ASPS & ASPSCR1-TFE3 & TFE3+ & Sunitinib, cediranib \\
\hline CCS & EWSR1-CREB1/-ATF1 & S100+ HMB45+ Melan-A+ & \\
\hline Chordoma & & $\mathrm{CK}+\mathrm{S} 100+$ brachyury+ & \\
\hline ES & Loss of INI1 & INI1- & \\
\hline GIST & KIT/PDGFRA/SDHA/-B/-C/-D & CD34+/- CD117+/- DOG1+/- & \\
\hline Lipoblastoma & PLAG1-HAS2/COL1A2/HMGA2 & & \\
\hline LMS & MYOCD loss of p53/ATRX & SMA+ desmin $+\mathrm{h}$-caldesmon+ & Pazopanib, gemcitabine, trabectidin \\
\hline Alveolar RMS & FOXO1-FGFR1/PAX3-FOXO1/-FOXO4/ & SMA+ Desmin+ MYOD1+ & Crizotinib, ceritinib, palbociclib, \\
\hline & -NCOA1/-NCOA2/INO80D/PAX7-FOXO1 & & $\begin{array}{l}\text { BMS-754807, cixutumumab, R1507 } \\
\text { anti-IGF1R antibody, vemurafenib, } \\
\text { dabrafenib, MEK inhibitor, selumetinib, } \\
\text { ERK2 inhibitor, EZH2 inhibitor }\end{array}$ \\
\hline Sclerosing RMS & $\begin{array}{l}\text { RAS,FGFR4,ERBB2,PIK3CA, PI3K, FBXW7, } \\
\text { NF1, TP53, CTNNB1,BCOR, MYOD1 }\end{array}$ & SMA+ desmin+ MYOD1+ & \\
\hline Spindle-cell lipoma & Loss of $R B 1$ & $\mathrm{CD} 34+\mathrm{RB}-$ & \\
\hline SS & SS18-SSX1/-SSX2/-SSX4/SS18L1-SSX1 & TLE1+ CKf + EMAf+ & Pazopanib \\
\hline TSGCT & CSF1-COL6A3/other & & $\begin{array}{l}\text { Imatinib, nilotinib, PLX3397, } \\
\text { emactuzumab }\end{array}$ \\
\hline
\end{tabular}


ity or ethmoid sinus. There is a striking predilection for women in the fifth decade of life. Histologically, this tumor shows an infiltrative growth pattern and resembles adult fibrosarcoma or monophasic synovial sarcoma. A classic "herringbone" pattern can be identified in most cases. Despite the cellularity, only rare mitotic figures are present. A characteristic finding in the majority of these neoplasms is an epithelial proliferation. This proliferation is composed of surface-type respiratory epithelium. A prominent hemangiopericytomatous vascular pattern is also present in a subset of these tumors. BSNS typically shows a unique, biphenotypic IHC staining pattern [81]. This unique dual phenotype can be explained by the recurrent rearrangements of PAX3, a transcription factor that promotes commitment along neural and myogenic lineages. Most BSNS harbor a pathognomonic PAX3MAML3 fusion; an alternative fusion partner gene is NCOA1. The tumors usually express at least focal S100, SMA, calponin, $B$-catenin, and factor XIIIa, and subset of tumors expresses focal EMA, CD34, desmin, and/or myogenin. None of the cases reacted with SOX10. An extended IHC panel including $\beta$-catenin and SOX10 as well as NGS supports the diagnosis of BSNS [82-84].

Bone and soft-tissue neoplasms are listed in Table 3 according to their genetic alterations and therapeutic relevance [85-104].

\section{Concluding Remarks}

To date, approximately $50 \%$ of the described soft-tissue tumors and $25 \%$ of bone tumors harbor recurrent genetic alterations that can be used to reach a precise diagnosis. It is most likely that using NGS more tumor entities will be characterized by recurrent genetic changes. Con- sidering the number of newly described entities after the release of the recent WHO 2013 classification, one can suspect that the number of new tumor entities will still grow in the future. Although HE morphology in combination with IHC (and FISH) is the golden standard in the diagnosis of bone and soft-tissue tumors, NGS can be used as an independent diagnostic tool to confirm a given diagnosis and can reduce interobserver variability. In addition, classification of the tumors according to the genetic alteration will allow the development of more targeted treatment options. Taking into account that some rare bone and soft-tissue tumors show similar or the same genetic alterations as more common tumor entities, one can hope that patients suffering from these rare tumors will have the opportunity to participate in basket trials based on the genetic tumor fingerprint. NGS will hopefully provide information for new personalized treatment options and the identification of useful biomarkers.

Based on our single-center experience in NGS using the Ion AmpliSeq Cancer Hotspot Panel v2 and the Ion AmpliSeq Comprehensive Cancer Panel (Thermo Fisher Scientific) for mutational analyses as well as the Archer FusionPlex Sarcoma Kit (ArcherDX, Inc) to detect gene fusions in 26 genes since early 2016, we have experienced NGS as a very sensitive method to detect genetic alterations. In our experience, the use of the Archer FusionPlex Sarcoma Kit is superior to FISH as an auxiliary tool in the routine diagnostic approach of soft-tissue and bone tumors.

\section{Disclosure Statement}

The authors have no conflict of interest to declare.

\section{References}

1 Fletcher CDM, Bridge JA, Hogendoorn P, Mertens F: WHO Classification of Tumours of Soft Tissue and Bone, ed 4. Lyon, IARC Press, 2013, p 468.

2 https://my.clevelandclinic.org/ccf/media/ files/Pathology/TechnicalBriefs-Jan2006FISHforSarcomaTranslocation.pdf.

$3 \mathrm{http} / / /$ portals.clevelandclinic.org/portals/66/ pdf/technical-briefs/fish-for-mdm2-gene-amplification-a-valuable-tool-in-the-differentialdiagnosis-of-lipomatous-neoplasms.pdf.

4 Weaver J, Downs-Kelly E, Goldblum JR, Turner S, Kulkarni S, Tubbs RR, et al: Fluorescence in situ hybridization for MDM2 gene amplification as a diagnostic tool in lipo-

NGS as a Diagnostic Tool for Bone and Soft-Tissue Tumors

\footnotetext{
Soft-Tissue Tumors
}

matous neoplasms. Mod Pathol 2008;21:943949.

5 Huang SC, Zhang L, Sung YS, Chen CL, Kao YC, Agaram NP, et al: Secondary EWSR1 gene abnormalities in SMARCB1-deficient tumors with 22q11-12 regional deletions: Potential pitfalls in interpreting EWSR1 FISH results. Genes Chromosomes Cancer 2016; 55:767-776.

6 Jain S, Xu R, Prieto VG, Lee P: Molecular classification of soft tissue sarcomas and its clinical applications. Int J Clin Exp Pathol 2010;3: 416-428.

7 Marino-Enriquez A, Bovee JV: Molecular pathogenesis and diagnostic, prognostic and predictive molecular markers in sarcoma. Surg Pathol Clin 2016;9:457-473.

8 Cleven AH, Briaire-de Bruijn I, Szuhai K, Bovee JV: DOG1 expression in giant-cell-containing bone tumours. Histopathology 2016; 68:942-945.

9 Konishi E, Nakashima Y, Iwasa Y, Nakao R, Yanagisawa A: Immunohistochemical analysis for Sox9 reveals the cartilaginous character of chondroblastoma and chondromyxoid fibroma of the bone. Hum Pathol 2010;41:208-213.

10 Lin G, Doyle LA: An update on the application of newly described immunohistochemical markers in soft tissue pathology. Arch Pathol Lab Med 2015;139:106-121.

Pathobiology 2017;84:323-338

DOI: $10.1159 / 000478662$ 
11 Maues De Paula A, Vasiljevic A, Giorgi R, Gomez-Brouchet A, Aubert S, Leroy X, et al: A diagnosis of giant cell-rich tumour of bone is supported by p63 immunohistochemistry, when more than $50 \%$ of cells is stained. Virchows Arch 2014;465:487-494.

12 Presneau N, Baumhoer D, Behjati S, Pillay N, Tarpey P, Campbell PJ, et al: Diagnostic value of H3F3A mutations in giant cell tumour of bone compared to osteoclast-rich mimics. J Pathol Clin Res 2015;1:113-123.

13 Cleven AH, Hocker S, Briaire-de Bruijn I, Szuhai K, Cleton-Jansen AM, Bovee JV: Mutation analysis of H3F3A and $\mathrm{H} 3 \mathrm{~F} 3 \mathrm{~B}$ as a diagnostic tool for giant cell tumor of bone and chondroblastoma. Am J Surg Pathol 2015;39: 1576-1583.

14 Behjati S, Tarpey PS, Presneau N, Scheipl S, Pillay N, Van Loo P, et al: Distinct H3F3A and H3F3B driver mutations define chondroblastoma and giant cell tumor of bone. Nat Genet 2013;45:1479-1482.

15 Sarungbam J, Agaram N, Hwang S, Lu C, Wang L, Healey J, et al: Symplastic/pseudoanaplastic giant cell tumor of the bone. Skeletal Radiol 2016;45:929-935.

16 Panoutsakopoulos G, Pandis N, Kyriazoglou I, Gustafson P, Mertens F, Mandahl N: Recurrent $t(16 ; 17)(q 22 ; p 13)$ in aneurysmal bone cysts. Genes Chromosomes Cancer 1999;26: 265-266.

17 Oliveira AM, Perez-Atayde AR, Dal Cin P, Gebhardt MC, Chen CJ, Neff JR, et al: Aneurysmal bone cyst variant translocations upregulate USP6 transcription by promoter swapping with the ZNF9, COL1A1, TRAP150, and OMD genes. Oncogene 2005;24:34193426.

18 Kim MJ, Cho KJ, Ayala AG, Ro JY: Chondrosarcoma: with updates on molecular genetics. Sarcoma 2011;2011:405437.

19 Pansuriya TC, van Eijk R, d'Adamo P, van Ruler MA, Kuijjer ML, Oosting J, et al: Somatic mosaic IDH1 and IDH2 mutations are associated with enchondroma and spindle cell hemangioma in Ollier disease and Maffucci syndrome. Nat Genet 2011;43:1256-1261.

20 Amary MF, Bacsi K, Maggiani F, Damato S, Halai D, Berisha F, et al: IDH1 and IDH2 mutations are frequent events in central chondrosarcoma and central and periosteal chondromas but not in other mesenchymal tumours. J Pathol 2011;224:334-343.

21 Jour G, Liu Y, Ricciotti R, Pritchard C, Hoch BL: Glandular differentiation in dedifferentiated chondrosarcoma: molecular evidence of a rare phenomenon. Hum Pathol 2015;46: 1398-1404

22 Kerr DA, Lopez HU, Deshpande V, Hornicek FJ, Duan Z, Zhang Y, et al: Molecular distinction of chondrosarcoma from chondroblastic osteosarcoma through IDH1/2 mutations. Am J Surg Pathol 2013;37:787-795.

23 Stein EM: Molecular pathways: IDH2 mutations-co-opting cellular metabolism for malignant transformation. Clin Cancer Res 2016;22:16-19.
24 Speetjens FM, de Jong Y, Gelderblom H, Bovee JV: Molecular oncogenesis of chondrosarcoma: impact for targeted treatment. Curr Opin Oncol 2016;28:314-322.

25 Tinoco G, Wilky BA, Paz-Mejia A, Rosenberg A, Trent JC: The biology and management of cartilaginous tumors: a role for targeting isocitrate dehydrogenase. Am Soc Clin Oncol Educ Book 2015:e648-e655.

26 Yoshida A, Ushiku T, Motoi T, Shibata T, Beppu Y, Fukayama M, et al: Immunohistochemical analysis of MDM2 and CDK4 distinguishes low-grade osteosarcoma from benign mimics. Mod Pathol 2010;23:12791288.

27 Salinas-Souza C, De Andrea C, Bihl M, Kovac $\mathrm{M}$, Pillay N, Forshew T, et al: GNAS mutations are not detected in parosteal and lowgrade central osteosarcomas. Mod Pathol 2015;28:1336-1342.

28 Doyle LA, Wong KK, Bueno R, Dal Cin P, Fletcher JA, Sholl LM, et al: Ewing sarcoma mimicking atypical carcinoid tumor: detection of unexpected genomic alterations demonstrates the use of next generation sequencing as a diagnostic tool. Cancer Genet 2014; 207:335-339.

29 Szuhai K, Cleton-Jansen AM, Hogendoorn PC, Bovee JV: Molecular pathology and its diagnostic use in bone tumors. Cancer Genet 2012;205:193-204.

30 Machado I, Navarro S, Llombart-Bosch A: Ewing sarcoma and the new emerging Ewinglike sarcomas: (CIC and BCOR-rearrangedsarcomas). A systematic review. Histol Histopathol 2016;31:1169-1181.

31 Chebib I, Jo VY: Round cell sarcoma with CIC-DUX4 gene fusion: discussion of the distinctive cytomorphologic, immunohistochemical, and molecular features in the differential diagnosis of round cell tumors. Cancer Cytopathol 2016;124:350-361.

32 Specht K, Zhang L, Sung YS, Nucci M, Dry S, Vaiyapuri S, et al: Novel BCOR-MAML3 and ZC3H7B-BCOR gene fusions in undifferentiated small blue round cell sarcomas. Am J Surg Pathol 2016;40:433-442.

33 Italiano A, Sung YS, Zhang L, Singer S, Maki RG, Coindre JM, et al: High prevalence of CIC fusion with double-homeobox (DUX4) transcription factors in EWSR1-negative undifferentiated small blue round cell sarcomas. Genes Chromosomes Cancer 2012;51:207218.

34 Haidar A, Arekapudi S, DeMattia F, Abu-Isa E, Kraut M: High-grade undifferentiated small round cell sarcoma with $\mathrm{t}(4 ; 19)$ (q35;q13.1) CIC-DUX4 fusion: emerging entities of soft tissue tumors with unique histopathologic features - a case report and literature review. Am J Case Rep 2015;16: 87-94.

35 Specht K, Sung YS, Zhang L, Richter GH, Fletcher CD, Antonescu CR: Distinct transcriptional signature and immunoprofile of CIC-DUX4 fusion-positive round cell tumors compared to EWSR1-rearranged Ewing sar- comas: further evidence toward distinct pathologic entities. Genes Chromosomes Cancer 2014;53:622-633.

36 Shibayama T, Okamoto T, Nakashima Y, Kato T, Sakurai T, Minamiguchi S, et al: Screening of BCOR-CCNB3 sarcoma using immunohistochemistry for CCNB3: a clinicopathological report of three pediatric cases. Pathol Int 2015;65:410-414.

37 Kao YC, Sung YS, Zhang L, Jungbluth AA, Huang SC, Argani P, et al: BCOR overexpression is a highly sensitive marker in round cell sarcomas with BCOR genetic abnormalities. Am J Surg Pathol 2016;40:1670-1678.

38 Panagopoulos I, Gorunova L, Bjerkehagen B, Boye K, Heim S: Chromosome aberrations and HEY1-NCOA2 fusion gene in a mesenchymal chondrosarcoma. Oncol Rep 2014;32: $40-44$.

39 Nyquist KB, Panagopoulos I, Thorsen J, Haugom L, Gorunova L, Bjerkehagen $\mathrm{B}$, et al: Whole-transcriptome sequencing identifies novel IRF2BP2-CDX1 fusion gene brought about by translocation $\mathrm{t}(1 ; 5)(\mathrm{q} 42 ; \mathrm{q} 32)$ in mesenchymal chondrosarcoma. PLoS One 2012; 7:e49705.

40 Fritchie KJ, Jin L, Ruano A, Oliveira AM, Rubin BP: Are meningeal hemangiopericytoma and mesenchymal chondrosarcoma the same? A study of HEY1-NCOA2 fusion. Am J Clin Pathol 2013;140:670-674.

41 Zhang N, Liu H, Yue G, Zhang Y, You J, Wang $\mathrm{H}$ : Molecular heterogeneity of Ewing sarcoma as detected by ion torrent sequencing. PLoS One 2016;11:e0153546.

42 Jiang Y, Subbiah V, Janku F, Ludwig JA, Naing A, Benjamin RS, et al: Novel secondary somatic mutations in Ewing's sarcoma and desmoplastic small round cell tumors. PLoS One 2014;9:e93676.

43 Ikeue T, Ohi I, Noguchi S, Fukao A, Terashita $\mathrm{S}$, Horikawa S, et al: Desmoplastic small round cell tumor of the pleura successfully treated with a lower dose of pazopanib. Intern Med 2016;55:2463-2467.

44 Frezza AM, Benson C, Judson IR, Litiere S, Marreaud S, Sleijfer S, et al: Pazopanib in advanced desmoplastic small round cell tumours: a multi-institutional experience. Clin Sarcoma Res 2014;4:7.

45 Italiano A, Kind M, Cioffi A, Maki RG, Bui B: Clinical activity of sunitinib in patients with advanced desmoplastic round cell tumor: a case series. Target Oncol 2013;8:211-213.

46 Naing A, LoRusso P, Fu S, Hong DS, Anderson $\mathrm{P}$, Benjamin RS, et al: Insulin growth factor-receptor (IGF-1R) antibody cixutumumab combined with the mTOR inhibitor temsirolimus in patients with refractory Ewing's sarcoma family tumors. Clin Cancer Res 2012;18:2625-2631.

47 Lamhamedi-Cherradi SE, Menegaz BA, Ramamoorthy V, Vishwamitra D, Wang Y, Maywald RL, et al: IGF-1R and mTOR blockade: novel resistance mechanisms and synergistic drug combinations for Ewing sarcoma. J Natl Cancer Inst 2016;108:djw182. 
48 Harlow ML, Maloney N, Roland J, Guillen Navarro MJ, Easton MK, Kitchen-Goosen SM, et al: Lurbinectedin inactivates the Ewing sarcoma oncoprotein EWS-FLI1 by redistributing it within the nucleus. Cancer Res 2016; 76:6657-6668.

49 Anderson PM, Bielack SS, Gorlick RG, Skubitz K, Daw NC, Herzog CE, et al: A phase II study of clinical activity of SCH 717454 (robatumumab) in patients with relapsed osteosarcoma and Ewing sarcoma. Pediatr Blood Cancer 2016;63:1761-1770.

50 Frappaz D, Federico SM, Pearson AD, Gore L, Macy ME, DuBois SG, et al: Phase 1 study of dalotuzumab monotherapy and ridaforolimus-dalotuzumab combination therapy in paediatric patients with advanced solid tumours. Eur J Cancer 2016;62:9-17.

51 Tanaka M, Kato K, Gomi K, Matsumoto M, Kudo H, Shinkai M, et al: Perivascular epithelioid cell tumor with SFPQ/PSF-TFE3 gene fusion in a patient with advanced neuroblastoma. Am J Surg Pathol 2009;33:1416-1420.

52 Argani P, Aulmann S, Illei PB, Netto GJ, Ro J, Cho HY, et al: A distinctive subset of PEComas harbors TFE3 gene fusions. Am J Surg Pathol 2010;34:1395-1406.

53 Shen Q, Rao Q, Xia QY, Yu B, Shi QL, Zhang RS, et al: Perivascular epithelioid cell tumor (PEComa) with TFE3 gene rearrangement: clinicopathological, immunohistochemical, and molecular features. Virchows Arch 2014; 465:607-613.

54 Rao Q, Wang Y, Xia QY, Shi SS, Shen Q, Tu $\mathrm{P}$, et al: Cathepsin $\mathrm{K}$ in the immunohistochemical diagnosis of melanocytic lesions. Int J Clin Exp Pathol 2014;7:1132-1139.

55 Agaram NP, Sung YS, Zhang L, Chen CL, Chen HW, Singer S, et al: Dichotomy of genetic abnormalities in PEComas with therapeutic implications. Am J Surg Pathol 2015; 39:813-825.

56 Schoolmeester JK, Dao LN, Sukov WR, Wang L, Park KJ, Murali R, et al: TFE3 translocation-associated perivascular epithelioid cell neoplasm (PEComa) of the gynecologic tract: morphology, immunophenotype, differential diagnosis. Am J Surg Pathol 2015;39:394-404.

57 Martignoni G, Pea M, Zampini C, Brunelli M, Segala D, Zamboni G, et al: PEComas of the kidney and of the genitourinary tract. Semin Diagn Pathol 2015;32:140-159.

58 Huang SC, Zhang L, Sung YS, Chen CL, Krausz T, Dickson BC, et al: Frequent FOS gene rearrangements in epithelioid hemangioma: a molecular study of 58 cases with morphologic reappraisal. Am J Surg Pathol 2015;39:1313-1321.

59 Antonescu CR, Chen HW, Zhang L, Sung YS, Panicek D, Agaram NP, et al: ZFP36-FOSB fusion defines a subset of epithelioid hemangioma with atypical features. Genes Chromosomes Cancer 2014;53:951-959.

60 Ide YH, Tsukamoto Y, Ito T, Watanabe T, Nakagawa N, Haneda T, et al: Penile pseudomyogenic hemangioendothelioma/epithelioid sarcoma-like hemangioendothelioma with a novel pattern of SERPINE1-FOSB fusion detected by RT-PCR - report of a case. Pathol Res Pract 2015;211:415-420.

61 Walther C, Tayebwa J, Lilljebjorn H, Magnusson L, Nilsson J, von Steyern FV, et al: A novel SERPINE1-FOSB fusion gene results in transcriptional up-regulation of FOSB in pseudomyogenic haemangioendothelioma. J Pathol 2014;232:534-540.

62 Trombetta D, Magnusson L, von Steyern FV, Hornick JL, Fletcher CD, Mertens F: Translocation $\mathrm{t}(7 ; 19)(\mathrm{q} 22 ; \mathrm{q} 13)$ - a recurrent chromosome aberration in pseudomyogenic hemangioendothelioma? Cancer Genet 2011;204: 211-215.

63 Puls F, Niblett A, Clarke J, Kindblom LG, McCulloch T: YAP1-TFE3 epithelioid hemangioendothelioma: a case without vasoformation and a new transcript variant. Virchows Arch 2015;466:473-478.

64 Antonescu CR, Le Loarer F, Mosquera JM, Sboner A, Zhang L, Chen CL, et al: Novel YAP1-TFE3 fusion defines a distinct subset of epithelioid hemangioendothelioma. Genes Chromosomes Cancer 2013;52:775-784.

65 Shibuya R, Matsuyama A, Shiba E, Harada H, Yabuki K, Hisaoka M: CAMTA1 is a useful immunohistochemical marker for diagnosing epithelioid haemangioendothelioma. Histopathology 2015;67:827-835.

66 Brenn T, Fletcher CD: Radiation-associated cutaneous atypical vascular lesions and angiosarcoma: clinicopathologic analysis of 42 cases. Am J Surg Pathol 2005;29:983-996.

67 Mentzel T, Schildhaus HU, Palmedo G, Buttner R, Kutzner H: Postradiation cutaneous angiosarcoma after treatment of breast carcinoma is characterized by MYC amplification in contrast to atypical vascular lesions after radiotherapy and control cases: clinicopathological, immunohistochemical and molecular analysis of 66 cases. Mod Pathol 2012; 25:75-85.

68 Cornejo KM, Deng A, Wu H, Cosar EF, Khan A, St Cyr M, et al: The utility of MYC and FLT4 in the diagnosis and treatment of postradiation atypical vascular lesion and angiosarcoma of the breast. Hum Pathol 2015;46: 868-875.

69 Antonescu CR, Zhang L, Nielsen GP, Rosenberg AE, Dal Cin P, Fletcher CD: Consistent $t(1 ; 10)$ with rearrangements of TGFBR3 and MGEA5 in both myxoinflammatory fibroblastic sarcoma and hemosiderotic fibrolipomatous tumor. Genes Chromosomes Cancer 2011;50:757-764.

70 Guillou L, Benhattar J, Gengler C, Gallagher G, Ranchere-Vince D, Collin F, et al: Translocation-positive low-grade fibromyxoid sarcoma: clinicopathologic and molecular analysis of a series expanding the morphologic spectrum and suggesting potential relationship to sclerosing epithelioid fibrosarcoma: a study from the French Sarcoma Group. Am J Surg Pathol 2007;31:1387-1402.

71 Cheah AL, Goldblum JR, Billings SD: Molecular diagnostics complementing morphology in superficial mesenchymal tumors. Semin Diagn Pathol 2013;30:95-109.

72 Doyle LA, Moller E, Dal Cin P, Fletcher CD, Mertens F, Hornick JL: MUC4 is a highly sensitive and specific marker for low-grade fibromyxoid sarcoma. Am J Surg Pathol 2011;35: 733-741.

73 Doyle LA, Wang WL, Dal Cin P, Lopez-Terrada D, Mertens F, Lazar AJ, et al: MUC4 is a sensitive and extremely useful marker for sclerosing epithelioid fibrosarcoma: association with FUS gene rearrangement. Am J Surg Pathol 2012;36:1444-1451.

74 Fritchie KJ, Goldblum JR, Tubbs RR, Sun Y, Carver P, Billings SD, et al: The expanded histologic spectrum of myxoid liposarcoma with an emphasis on newly described patterns: implications for diagnosis on small biopsy specimens. Am J Clin Pathol 2012;137:229-239.

75 Le Loarer F, Zhang L, Fletcher CD, Ribeiro A, Singer S, Italiano A, et al: Consistent SMARCB1 homozygous deletions in epithelioid sarcoma and in a subset of myoepithelial carcinomas can be reliably detected by FISH in archival material. Genes Chromosomes Cancer 2014;53:475-486.

76 Flucke U, Tops BB, Verdijk MA, van Cleef PJ, van Zwam PH, Slootweg PJ, et al: NR4A3 rearrangement reliably distinguishes between the clinicopathologically overlapping entities myoepithelial carcinoma of soft tissue and cellular extraskeletal myxoid chondrosarcoma. Virchows Arch 2012;460:621-628.

77 Jo VY, Fletcher CD: Myoepithelial neoplasms of soft tissue: an updated review of the clinicopathologic, immunophenotypic, and genetic features. Head Neck Pathol 2015;9:32-38.

78 Rekhi B, Sable M, Jambhekar NA: Histopathological, immunohistochemical and molecular spectrum of myoepithelial tumours of soft tissues. Virchows Arch 2012;461:687-697.

79 Nishio J, Iwasaki H, Nabeshima K, Naito M: Cytogenetics and molecular genetics of myxoid soft-tissue sarcomas. Genet Res Int 2011; 2011:497148.

80 Agaram NP, Zhang L, Sung YS, Chen CL, Chung CT, Antonescu CR, et al: Recurrent NTRK1 gene fusions define a novel subset of locally aggressive lipofibromatosis-like neural tumors. Am J Surg Pathol 2016;40:1407-1416.

81 Lewis JT, Oliveira AM, Nascimento AG, Schembri-Wismayer D, Moore EA, Olsen $\mathrm{KD}$, et al: Low-grade sinonasal sarcoma with neural and myogenic features: a clinicopathologic analysis of 28 cases. Am J Surg Pathol 2012;36:517-525.

82 Huang SC, Ghossein RA, Bishop JA, Zhang L, Chen TC, Huang HY, et al: Novel PAX3NCOA1 fusions in biphenotypic sinonasal sarcoma with focal rhabdomyoblastic differentiation. Am J Surg Pathol 2016;40:51-59.

83 Rooper LM, Huang SC, Antonescu CR, Westra WH, Bishop JA: Biphenotypic sinonasal sarcoma: an expanded immunoprofile including consistent nuclear beta-catenin positivity and absence of SOX10 expression. Hum Pathol 2016;55:44-50.
NGS as a Diagnostic Tool for Bone and Soft-Tissue Tumors
Pathobiology 2017;84:323-338 DOI: $10.1159 / 000478662$ 
84 Fritchie KJ, Jin L, Wang X, Graham RP, Torbenson MS, Lewis JE, et al: Fusion gene profile of biphenotypic sinonasal sarcoma: an analysis of 44 cases. Histopathology 2016;69:930936.

85 Sukov WR, Franco MF, Erickson-Johnson M, Chou MM, Unni KK, Wenger DE, et al: Frequency of USP6 rearrangements in myositis ossificans, brown tumor, and cherubism: molecular cytogenetic evidence that a subset of "myositis ossificans-like lesions" are the early phases in the formation of soft-tissue aneurysmal bone cyst. Skeletal Radiol 2008;37: 321-327.

86 Oliveira AM, Chou MM: USP6-induced neoplasms: the biologic spectrum of aneurysmal bone cyst and nodular fasciitis. Hum Pathol 2014;45:1-11.

87 Yoshida A, Tsuta K, Ohno M, Yoshida M, Narita Y, Kawai A, et al: STAT6 immunohistochemistry is helpful in the diagnosis of solitary fibrous tumors. Am J Surg Pathol 2014; 38:552-559.

88 Yang CY, Liau JY, Huang WJ, Chang YT, Chang MC, Lee JC, et al: Targeted next-generation sequencing of cancer genes identified frequent TP53 and ATRX mutations in leiomyosarcoma. Am J Transl Res 2015;7:20722081.

89 Antonescu CR, Suurmeijer AJ, Zhang L, Sung YS, Jungbluth AA, Travis WD, et al: Molecular characterization of inflammatory myofibroblastic tumors with frequent ALK and ROS1 gene fusions and rare novel RET rearrangement. Am J Surg Pathol 2015;39:957967.
90 Aitken SJ, Presneau N, Kalimuthu S, Dileo P, Berisha F, Tirabosco R, et al: Next-generation sequencing is highly sensitive for the detection of beta-catenin mutations in desmoidtype fibromatoses. Virchows Arch 2015;467: 203-210.

91 Cassier PA, Italiano A, Gomez-Roca CA, Le Tourneau C, Toulmonde M, Cannarile MA, et al: CSF1R inhibition with emactuzumab in locally advanced diffuse-type tenosynovial giant cell tumours of the soft tissue: a dose-escalation and dose-expansion phase 1 study. Lancet Oncol 2015;16:949-956.

92 Brahmi M, Vinceneux A, Cassier PA: Current systemic treatment options for tenosynovial giant cell tumor/pigmented villonodular synovitis: targeting the CSF1/CSF1R axis. Curr Treat Options Oncol 2016;17:10.

93 Tap WD, Wainberg ZA, Anthony SP, Ibrahim PN, Zhang C, Healey JH, et al: Structureguided blockade of CSF1R kinase in tenosynovial giant-cell tumor. N Engl J Med 2015; 373:428-437.

94 Staals EL, Ferrari S, Donati DM, Palmerini E: Diffuse-type tenosynovial giant cell tumour: current treatment concepts and future perspectives. Eur J Cancer 2016;63:34-40.

95 Huang HY, West RB, Tzeng CC, van de Rijn M, Wang JW, Chou SC, et al: Immunohistochemical and biogenetic features of diffusetype tenosynovial giant cell tumors: the potential roles of cyclin A, P53, and deletion of $15 \mathrm{q}$ in sarcomatous transformation. Clin Cancer Res 2008;14:6023-6032.

96 Yang J, Du X: Genomic and molecular aberrations in malignant peripheral nerve sheath tumor and their roles in personalized target therapy. Surg Oncol 2013;22:e53-e57.

97 Mertens F, Tayebwa J: Evolving techniques for gene fusion detection in soft tissue tumours. Histopathology 2014;64:151-162.
98 Warren M, Turpin BK, Mark M, Smolarek TA, Li X: Undifferentiated myxoid lipoblastoma with PLAG1-HAS2 fusion in an infant; morphologically mimicking primitive myxoid mesenchymal tumor of infancy (PMMTI) - diagnostic importance of cytogenetic and molecular testing and literature review. Cancer Genet 2016;209:21-29.

99 Davis IJ, McFadden AW, Zhang Y, Coxon A, Burgess TL, Wagner AJ, et al: Identification of the receptor tyrosine kinase c-Met and its ligand, hepatocyte growth factor, as therapeutic targets in clear cell sarcoma. Cancer Res 2010;70:639-645.

100 Antonescu CR, Dal Cin P, Nafa K, Teot LA, Surti U, Fletcher CD, et al: EWSR1-CREB1 is the predominant gene fusion in angiomatoid fibrous histiocytoma. Genes Chromosomes Cancer 2007;46:1051-1060.

101 Casali PG: Histology- and non-histologydriven therapy for treatment of soft tissue sarcomas. Ann Oncol 2012;23(suppl 10): x167-x169.

102 Kohsaka S, Shukla N, Ameur N, Ito T, Ng $\mathrm{CK}$, Wang L, et al: A recurrent neomorphic mutation in MYOD1 defines a clinically aggressive subset of embryonal rhabdomyosarcoma associated with PI3K-AKT pathway mutations. Nat Genet 2014;46:595600 .

103 Herrero Martin D, Boro A, Schafer BW: Cell-based small-molecule compound screen identifies fenretinide as potential therapeutic for translocation-positive rhabdomyosarcoma. PLoS One 2013;8:e55072.

104 Shern JF, Yohe ME, Khan J: Pediatric rhabdomyosarcoma. Crit Rev Oncog 2015;20: 227-243. 